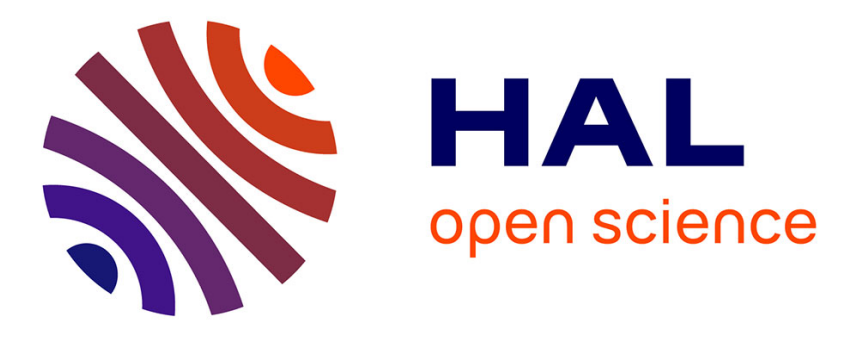

\title{
Patent quality and value in discrete and cumulative innovation
}

Justus Baron, Henry Delcamp

\section{To cite this version:}

Justus Baron, Henry Delcamp. Patent quality and value in discrete and cumulative innovation. Scientometrics, 2012, 90 (2), pp.581-606. 10.1007/s11192-011-0532-5 . hal-00488275v2

\section{HAL Id: hal-00488275}

\section{https://hal-mines-paristech.archives-ouvertes.fr/hal-00488275v2}

Submitted on 16 Nov 2010

HAL is a multi-disciplinary open access archive for the deposit and dissemination of scientific research documents, whether they are published or not. The documents may come from teaching and research institutions in France or abroad, or from public or private research centers.
L'archive ouverte pluridisciplinaire HAL, est destinée au dépôt et à la diffusion de documents scientifiques de niveau recherche, publiés ou non, émanant des établissements d'enseignement et de recherche français ou étrangers, des laboratoires publics ou privés. 
Justus Baron \& Henry Delcamp

Working Paper 2010-07

Cerna, Centre d'économie industrielle

MINES ParisTech

60, boulevard Saint Michel

75272 Paris Cedex 06 - France

Tél. : 33 (1) 40519000

November 2010 


\title{
Patent Quality and Value in Discrete and Cumulative Innovation
}

\author{
Cerna Working Paper 2010-07
}

Justus Baron ${ }^{1}$, Henry Delcamp ${ }^{2}$

November 11, 2010

\begin{abstract}
This article compares the relationship between patent quality and patent value in discrete and cumulative innovation. Using factor analysis and a set of various commonly used patent quality indicators including claims, citations and family size, we build a quality factor jointly driving all indicators for 9255 patents. We then test the significance of this quality factor for predicting patent renewal after 4, 8 and 12 years in an ordered logistic regression. Whereas we establish a robust and significant link between patent quality and value in samples of discrete and complex technology patents, there is no significant link for patents that are essential to technological standards. Consistently, neither the quality factor nor any single indicator allows predicting litigation on an essential patent. We conclude that while there is a robust link between patent quality and value in discrete innovation, this link is much weaker in cumulative innovation. Nevertheless, this affects only narrow, yet highly relevant, technological fields. There is no evidence that cumulativeness affects the relationship between quality and value in whole technological classes classified as "complex" by the literature.
\end{abstract}

\footnotetext{
Cerna, Mines ParisTech
}

${ }^{2}$ Cerna, Mines ParisTech 


\section{Introduction}

Patents play an important role in modern economies, and especially in the growing sector of Information and Communication Technologies (ICT). At the same time, especially in the ICT sector, the role played by patents is seen with increasing suspicion. While the number of ICT patents increases sharply, it is debated whether this increase in patents reflects an increase in innovation. It is a widely shared belief that an important share of the numerous ICT patents is of questionable quality and low commercial value. Furthermore, there is skepticism about the contribution of these numerous patents to technological progress in ICT industries that is characterized by strongly cumulative innovation. Many scholars raise concerns that cumulative innovation might be stifled in what develops to become a dense "patent thicket".

Patent thickets are webs of overlapping and mutually blocking patents held by different owners. Mutually blocking patent rights result from cumulative innovation, where no technological component can be marketed individually without the technological complements potentially protected by patent rights of different companies. Patent thickets have a clear impact on patent strategies, as they provide incentives to file blocking patents. Blocking patents are filed to force companies practicing an existing technology into licensing and profit sharing, rather than to develop a new activity on a production market. For many economists, patent thickets weaken the patent system by reducing returns on significant innovations through patent inflation and litigation, while allowing "patent trolls" to earn much on patents of dubious technological significance. The core prediction of the patent thicket theory is thus that the link between patent quality and patent value erodes. If the link between the value of a patent and the significance of the underlying innovation is weakened, so is the capacity of the patent system to reward innovators for socially desirable innovation activity. We will therefore address the crucial issue of the link between patent quality and patent value with a special focus on those fields where innovation is most cumulative.

Probably the most prominent sector characterized by cumulative innovation is ICT, and more particularly those markets shaped by standardization. Elsewhere, one of the main debates around standardization concerns the sharing of royalty surplus between the Intellectual Property owners of cumulative innovation (Swanson \& Baumol, 2005; Salant, 2009). Standardization is a common feature of modern ICT industries and conditions highly profitable markets such as mobile telephony, wireless communication, digital data processing and consumer electronics. Standards are means of ensuring compatibility between technological components. Standardization thus locks in the markets into technological options and ties complementary technologies together. Often, these technologies are protected by essential patents. A patent is said essential for a standard if there is no possibility of implementing the standard without infringing upon the standard. Through standardization, these patents thus gain blocking power over the whole standard. Important cases of litigation, such as the cases on the conduct of Qualcomm and Rambus, provide evidence of strong disagreements among companies, as manufacturing companies claim to be "held up" by owners of essential patents asking for disproportionate royalties. Competition law and the Intellectual Property rules of Standardization Organizations provide for a specific regime of Reasonable and Non-Discriminatory Licensing Conditions, but industry participants disagree on whether this regime is efficient in yielding reasonable prices for licensing essential patents.

Going beyond the narrowly defined, yet extremely important, technology markets around formal standardization, there are attempts in the literature to identify whole technological 
classes in which technology is more cumulative. These attempts yielded a categorization of technology classes into discrete and complex technologies. Even though the concrete classification varies from study to study, ICT technologies are consistently classified as complex technology field. These technologies are indeed characterized by high citation rates among patents, indicating stronger cumulativeness of research (Nagaokia, 2005), and a strong presence of mutually blocking patent rights (Von Graevenitz et al. 2009). In several empirical studies of the capacity of patent quality indicators to predict patent value, electronics and other "complex" technological fields have revealed a low link between quality indicators and value. Nevertheless, none of these studies has clearly established whether cumulativeness is driving this apparently lower link between indicators of patent quality and value. In particular, these studies do not tell whether the link is weaker because the link between quality and value is weakened or because the indicators are themselves less informative of the underlying concepts quality and value. It is an important contribution of the present study to disentangle these issues. Furthermore, we will analyze whether particularities of patents from "complex" technology classes are due to the cumulativeness of research by comparing random complex technology patents to patents that are essential to technological standard.

We will therefore study three different samples of patents. The first sample is made of patents declared as essential to technological standards, and allows testing directly the characteristics of cumulative innovation. In order to analyze whether these effects are specific to essential patents or rather relate to the broader technological field, we compare our sample of essential patents with a control sample of sibling patents from the same technological classes as the essential patents. We make sure that this sample consists only of patents from technological fields identified as "complex" by the related literature. Finally, we introduce a third sample of patents with the same application years as our two other samples, but randomly drawn from patent classes that are clearly identified as "discrete" by the related literature. We then compare the link between patent quality and value from sample to sample.

This is the first study using a broad range of patent quality indicators to address this issue. All these indicators are observable characteristics of a patent - like the number of claims or the number of times a patent is cited by posterior patents - that are believed to be driven by patent quality. Even though any of these indicators is likely to be noisy, using compound indicators reduces the noise and increases the likelihood of capturing the significance or quality of patents. Furthermore, we capture the value of patents by predicting the likelihood of renewal after 4,8 and 12 years of patent terms and check the robustness of our results by using litigation data as alternative measure of commercial value.

We will in a first step analyze the validity of the quality indicators. Our analysis concentrates on six indicators of patent quality: forward citations, backward citations, number of claims, family size, and originality and generality indices. Factor analysis will reveal that in all samples there are two rather than one common factor driving the data. We can identify a quality factor driven by forward citations, claims and family size that is consistent throughout the samples. These quality indicators have however a much stronger covariance in discrete than in complex technology patents. A second factor, which we identify as basicness or fundamentality of the patent, is particularly important for complex technology patents and especially for essential patents. Nevertheless, this factor is irrelevant for predicting patent value.

In a second step, we use the quality factor established through factor analysis to explain patent value through renewal and litigation analysis. In spite of the lower covariance of patent 
quality indicators in complex technologies, both the quality factor and single indicators perform well for predicting patent value and litigation in this sample. By contrast, in the sample of essential patents, neither compound nor single indicators have any predictive power for explaining patent renewal or litigation. We can rule out that this lack of explanatory power is due to weakness of quality indicators. Indeed, the indicators are even less noisy for essential patents than for the other patents from complex technology classes. Rather, we conclude that there is no link between patent quality and patent value in strongly cumulative innovation as for instance in standardized technologies. Nevertheless, this finding is specific to the sample of essential patents and cannot be generalized to the relevant patent classes.

The remainder of this article is organized as follows. Part I summarizes the literature and sketches the theoretical background of the analysis. Part II describes the data and discusses the construction of the samples. Part III summarizes the results of the factor analysis. In Part IV, we will describe how the quality factor performs in predicting patent value as measured through patent renewals. Part V discusses the implications of our results for policy and research methodology.

\section{Theoretical background, literature review}

It is the aim of this part to provide an overview over the literature. In the first part, we will summarize the economic literature on patent indicators and the measurement of patent quality. In the second part, we will discuss results of the literature using these indicators to analyze the relationship between patent quality and patent value. In both parts we will focus particularly on the distinction between discrete and cumulative innovation and between discrete and complex technology classes.

\section{I.1 Measuring patent quality and value: the literature on patent indicators}

There is a longstanding tradition in economic research to rely upon patent data to measure the output of innovative activity. Nevertheless, patents are very heterogeneous, as some patents are very important, while many patents are never used. As this heterogeneity of patents reduces the significance of patent counts as measure of innovation output, empirical research routinely weights patent counts by indicators of the importance of the underlying technology. This importance of the underlying technology is referred to as patent quality and could alternatively be defined as the size of the inventive step protected by the patent or as the relevance of the underlying technology for future use by follow-up innovators. This concept has also been referred to as social value of the patent, i.e. the value added by the protected technology independently of who appropriates this value.

Various strategies exist to compare the quality of patents: the literature has used e.g. expert rankings, case studies, or survey analysis. Nevertheless, these strategies are not available for studies of broad technological sectors with a very high number of relevant patents. Therefore the economic literature systematically relies upon indicators of patent quality. Indicators are quantitative patent characteristics that are easily observable and are thought to reflect patent quality. 
The most commonly used indicators are the number of citations a patent receives by posterior patents (so-called forward citations), the number of claims, and the size of the patent family (i.e. the number of international patent files with the same priority patent) (Griliches, 1990). Other indicators of patent quality include the number of backward cites, i.e. the number of patents cited as prior art and the patent's generality index (measuring the dispersion of prior art over technology classes) and originality index (measuring the dispersion of citing patents over technology classes). Table 1 summarizes the main indicators of patent quality used in the literature.

\begin{tabular}{|l|l|l|}
\hline \multicolumn{1}{|c|}{ Name of the Indicator } & \multicolumn{1}{|c|}{ Description } & \multicolumn{1}{c|}{ Justification } \\
\hline Forward cites & $\begin{array}{l}\text { Number of citations received } \\
\text { by posterior patents }\end{array}$ & $\begin{array}{l}\text { Indicates the relevance of the } \\
\text { patent for further research }\end{array}$ \\
\hline Backward cites & $\begin{array}{l}\text { The number of pritations made to } \\
\text { claims made in the patent }\end{array}$ & $\begin{array}{l}\text { Indicates the extent to which } \\
\text { the patent makes use of the } \\
\text { existing prior art }\end{array}$ \\
\hline Fumber of claims & $\begin{array}{l}\text { Indicates the breadth of the } \\
\text { technology claimed by the } \\
\text { patent holder } \\
\text { patents filed for the same } \\
\text { priority patent }\end{array}$ & $\begin{array}{l}\text { Indicates that a patent is } \\
\text { important on an international } \\
\text { scale, and that its holder is } \\
\text { willing to incur high } \\
\text { application costs }\end{array}$ \\
\hline Generality & $\begin{array}{l}\text { Dispersion of cited patents } \\
\text { over technology classes }\end{array}$ & $\begin{array}{l}\text { Indicates that the patent } \\
\text { draws from various sources, } \\
\text { increases the likelihood that } \\
\text { the patent is a fundamental } \\
\text { rather then incremental } \\
\text { innovation }\end{array}$ \\
\hline Originality & $\begin{array}{l}\text { Dispersion of citing patents } \\
\text { over technology classes }\end{array}$ & $\begin{array}{l}\text { Indicates that the patent has } \\
\text { been important for a broad } \\
\text { field of further research }\end{array}$ \\
\hline
\end{tabular}

Table 1 : Patent quality indicators

These indicators are often used indiscriminately in different sectors and to measure a vague and little defined patent quality. However, the indicators capture at best heterogeneous phenomena associated with the patents' quality. For example, the number of claims could indicate the breadth of a patent whereas forward cites measure technological significance for further research. These specific phenomena could be, according to the field and the aim of the study, more or less relevant for patent quality. Thus, these indicators may be, according to the sector, considered as more or less suited to a study of a specific situation. Consequently, assessing the performance of quality indicators is crucial.

For instance, the performance of the forward cites indicator has been repeatedly assessed and confirmed. Trajtenberg (1990-1) shows on a sample of computed tomography patents that more highly cited patents contribute more to consumer and producer welfare, Harhoff et al. (1999) show that patent holders value higher those of their patents that receive more citations, and Giummo (2003) finds that patents more often cited are more likely to be licensed. It has furthermore been shown that patents cited more frequently are more likely to be litigated (Lanjouw \& Schankerman, 1999) or to be included into technological standards (Rysman \& 
Simcoe, 2008). In a different approach, Lanjouw and Schankerman (2004) carry through a factor analysis on four indicators of patent quality and identify a strong covariance with one single common factor capturing an important part of the variance in the data. They argue that patent "quality" is the only underlying factor that could be thought of to jointly affect the number of claims, forward and backward cites and the size of the families. They furthermore argue that using a common underlying factor of various indicators rather than a single indicator allows reducing the noise and improves the capacities of indicators to approximate patent quality.

Probably, the most important challenge to the general use of patent quality indicators is the heterogeneity of the patent population. The functions and the mechanisms of patents can vary very much according to external factors, such as the type of assignee, the grant year and especially the field of technology. It is important in our context to make sure that for instance cumulativeness does not affect the capacity of indicators to measure quality adequately.

For several reasons the cumulativeness of a technology field could have an impact on the patent indicators of quality. For instance the density of the patent web in a complex industry mechanically affects the average number of citations. Independently of its quality, a patent will be cited more often if it covers a technological area where the propensity to patent is high. For the same reason, a patent in such a dense web will have to cite more previous art than a comparable patent in another field of the same technological sector.

Also firm strategies in the context of complex innovation can bias the indicators. Köhler, Blind and Thumm (2010) find that patents disclosed as essential to technological standards have more claims. Indeed, the existence of overlapping patents could provide incentives to raise the number of claims, as increasing the number of claims increases the chances of the patent to be relevant to future developments of a jointly held technology. On a different stance, overlapping IP in complex technologies may increase firms' incentives to file numerous patents for few innovations, thereby increasing the size of the families.

The fact that all the indicators are driven upwards or downwards in a particular technological field does not impede that variance inside a sample of patents from this technological field indicates differences in patent quality. For instance, Lanjouw and Schankerman (2004) in their factor analysis of four indicators over samples of patents from different technological fields identify a quality factor that is consistent over technological differences. Nevertheless, the covariance captured by this factor is lower in electronics, and the relative weights of the different indicators included in the factor are different. These results could indicate that even though the indicators still evidence a common quality factor in "complex" technology classes, they yield less consistent results than in discrete technologies.

We will thus test the consistency of our quality indicators throughout the samples before engaging into the econometric analysis of the link between patent quality and value. We want to make sure that differences in the link between patent quality indicators and patent value are not driven by the fact that the patent quality indicators perform differently well in indicating patent quality. 


\section{I.2 The link between patent quality and value: cumulative vs. discrete innovation}

Economic research draws a clear distinction between the notion of patent quality and the commercial value of the patent (Trajtenberg 1990-2). There are several ways to calculate the value of a patent: most important examples are the depreciated sum of expected cash flows, the expected sales price of the patent, or the contribution of the patent to the market value of the owning firm. The concept of patent value takes into account only the value added of the patent for its owner.

Many factors besides the quality or significance can determine a patent's value. An important issue is the ability of the owner to appropriate the value generated by the patent (Trajtenberg Henderson \& Jaffe, 1997). Even a technologically significant patent can be of low private value, when the owner is unable to appropriate the gains generated by the patent. In this case, the existence of externalities drives a divide between social and private value of the patent. Another possibility is that the owner of the patent does not have the capacities to practice the protected technology and market failures impede the sale of the patent at its real value. On the other hand even patents protecting only minor technological contributions can be of high value to their owner, if additionally to reaping the added value of the protected technology they allow leveraging on related innovations.

Several ways how patents leverage on related innovations are studied in the literature. For instance economists have come to acknowledge the importance of holding large patent portfolios. Indeed, each patent increases the value of the other patents held by the same patent owner, as patent portfolios shield the single patents from invalidation claims, leverage negotiation power, attract subsequent investment in applied research and increase the patent holder's say in patent politics and decision making (Wagner and Parchomovsky, 2005).

Many arguments pointing to a divergence between patent quality and patent value relate to the cumulativeness of research. For instance, Liu, Arthurs, Cullen and Alexander (2008) find that patents relating to sequential innovation held by the same owner are more valuable. In other contexts, it has been found that cumulative innovation has an incidence on patent value also when the various patents are held by different owners. For instance, a patent holder can extract substantial royalties from conduct known as patent ambush or holdup. These are practices where a patent holder deceives potential licensees on the existence of his property rights or on the extent of his royalty claims until sunk investments are incurred. The incidence of real or perceived patent holdup has led to various policy efforts to provide a regulatory framework for licensing patents in cumulative technology, most notably technological standards, as it is not clear that market mechanisms will yield prices that are in adequate proportion to the significance of the patent ${ }^{3}$.

An assumption underpinning these debates is that the link between patent quality and patent value is very important. If the returns on patents are disconnected from the technological contribution of the underlying innovation, the efficiency of the patent system as innovation

\footnotetext{
${ }^{3}$ A recent example is the drastically extended chapter on standardization in the draft guidelines on the applicability of European Competition Law to Horizontal Cooperation Agreements, see http://ec.europa.eu/competition/consultations/2010_horizontals/guidelines_en.pdf
} 
reward is at stake. An increasing strand of empirical literature has thus studied the link between patent quality and value. Hall, Jaffe \& Trajtenberg (2005) and Nagaoka (2005) analyze the correlation between patent quality indicators and the market value of the patent owner, and Lanjouw and Schankerman (1999) and Thomas (1999) analyze the impact of patent quality on the probability that a patent is renewed. Consistently, all studies evidence a strong link between quality and value, but there is also evidence for strong differences between technological fields.

Lanjouw and Schankerman (1999) use a compound factor of quality indicators (claims, forward cites, family size and backward cites) to predict patent litigation and renewal as measure of private value. They emphasize a strong link between patents' private value and indicators of quality; but this link is less obvious for the electronics sector. Hall et al. (2005) underline that the impact of patents weighted by citations on the estimation of firms' market value differs according to the technological sectors. They especially highlight that the impact of patent citations on market value is over 50\% higher for drugs than the average effect. This effect is lower for computers than that for the other sectors. They explain this difference by the opposition between complex and discrete technologies: "Computers and Communications is a group of complex product industries where any particular product may rely on various technologies embodied in several patents held by different firms. In this industry patents are largely valued for negotiating cross-licensing agreements, so their individual quality is not as important, although having them is". On the other hand, Nagaoka (2005) finds that patent quality measured by forward citations is more correlated with firm market value in ICT and other industries where innovation is cumulative.

All these papers build upon the idea that technologies can be categorized into complex and discrete technologies, whereby complex technologies are characterized by a dominance of cumulative innovation and a strong incidence of patent thickets ${ }^{4}$. This distinction originates in a paper of Levin \& all. from 1987 and has by now been studied by an extensive body of research $^{5}$. This research has established that firm strategies with respect to patents differ from complex to discrete technologies (Cohen, Nelson and Walsh, 2000). In complex technologies, many firms use patents for other reasons than excluding their rivals from the use of their technology. Most notably, many firms active in complex technologies rely heavily on crosslicensing agreements to cut their way through patent thickets ${ }^{6}$ (Giuri, 2010) and engage into patent portfolio races (Hall and Ziedonis, 2001). Hereby patent portfolios play an important role as "mass of negotiation". Thus, the way how patents create value could be different from discrete to complex technological fields. The value is no more derived from the right to use or to produce the technology but from the possibility to use the patent as a threat of exclusion and mass of negotiation. This argument is particularly relevant to specific technological sectors such as telecommunications or semi-conductors.

The extant literature thus draws a distinction between complex and discrete technology classes that is motivated by the more cumulative nature of innovation in complex technologies. Nevertheless, as underlined by Robin Jacob, innovation is in general essentially

\footnotetext{
${ }^{4}$ Harhoff and von Graevenitz (2009)

${ }^{5}$ Levin et al. (1987), Merges and Nelson (1990), Kusonoki, Nonaka and Nagata (1998), Cohen, Nelson and Walsh (2000)

${ }^{6}$ Patent thickets can be defined as: "a dense web of overlapping intellectual property rights that a company must hack its way through in order to actually commercialize new technology." (Shapiro, 2001)
} 
cumulative and it is therefore in the nature of the patent system to generate patent thickets ${ }^{7}$. Furthermore, even though differences between technological classes are widely attributed to implications of more or less cumulative innovation, there is so far no empirical analysis directly relating findings on the level of technological classes to the issue of cumulativeness.

In this paper we will disentangle the effects of cumulativeness from the technological class a patent belongs to. In order to do that, we will compare a sample of (complex) patents declared as essential to technological standards with a control sample of patents from exactly the same (complex) technology classes. Indeed, standardization is a process applying to cumulative innovation, as it ensures compatibility between various technological components. Indeed, the impact of cumulativeness on the value of the patents is particularly strong for essential patents and it seems particularly difficult to establish their value. This is evidenced through an extensive literature trying to establish a formula for measuring the value of essential patents and giving substance to the formula of Reasonable royalty rates inscribed into the rules of Standardization Organizations (Swanson \& Baumol, 2005; Salant, 2009).

We will thus directly address the question of the link between quality and value in cumulative and discrete innovation. We reproduce findings in the literature by comparing samples of complex and discrete technology patents. Introducing a sample of essential patents from the same technology classes as the sample of complex patents, we are able to analyze whether the differences between classes are effectively due to implications of cumulative innovation. Furthermore, we disentangle effects affecting the performance of indicators from effects affecting the link between quality and value. We now turn to a description of the construction of the database and provide descriptive statistics for the various samples.

\section{Data and Descriptive statistics}

\section{II.1 Construction of the samples and variables}

Our objective is to compare cumulative and discrete innovation on samples of complex and discrete technologies. As discussed, we introduced a third sample of standardized patents in order to highlight how our results are driven by implications of cumulativeness.

As data are most constrained for standardized patents, we first constituted a database of US patents that are essential to technological standards. This database is derived from patent disclosures at 8 standard setting organizations (SSOs) collected by Rysman and Simcoe and from the websites of seven different patent pools (lists of SSOs and patent pools can be found in the appendix 3). It comprises overall 3343 essential patents, out of which 993 are part of a patent pool.

By merging these patent lists with the NBER patent database, we inform the technology classes of 3128 patents and verify that the patents in our database cover technology that is

\footnotetext{
${ }^{7}$ Rt. Hon. Sir Robin Jacob (2008), "Patents and Pharmaceuticals - a Paper given on $29^{\text {th }}$ November at the Presentation of the Directorate-General of Competition's Preliminary Report of the Pharma-sector inquiry"
} 
classified as "complex" according to previous literature ${ }^{8}$. The concrete classification of technological sectors into complex or discrete technologies is still subject to debate. In our analysis, we will concentrate on clear cut cases of industries that are classified as complex or discrete according to several methodologies. Details on our selection of classes can be found in the annex 4.

Based on the remaining patents, we construct a sample of siblings. These are US patents with the same application year and the same technology class randomly chosen from the NBER patent database. This second sample is what we will call in the following the group of complex, non-standardized patents.

Finally, we build up a third sample of discrete patents. These are patents with the same application years as the patents in the other two samples, randomly chosen from a large range of discrete technology classes in the NBER patent database. The detailed, three-digit technology classes of both the complex and the discrete patent samples can be consulted in the annex.

Overall, we have 9255 patent observations. The NBER patent database yields information on citation flows and other important variables. We inform the number of forward cites (including and excluding self-cites), backward cites as well as the generality and originality indices, both building upon citation data. We furthermore retrieve the number of claims, the application year and the grant year. We complete this information on patents using the website of the European Patent Office www.espacenet.com, where we retrieve the size of the patent families and indications on renewals.

By merging the patent database with our own disclosure database, we obtain the concrete technological standard that 1.509 patents are essential to and the dates of disclosure. If one patent is disclosed as essential to several standards, we retain only the standard of the first disclosure. For every standard, we calculate the mean of the disclosure dates of all essential patents. For every patent, we generate an age_of_disclosure variable, defined as the difference between the disclosure date and the mean disclosure date for this particular standard. For the 993 pool patents, we use an earlier database including an age_of_input variable, defined as the difference between the date of input of a given patent and the date of input of the first patent in the pool. Even though differently constructed, age_of_disclosure and age_of_input both allow studying the chronological order of patents that are essential for the same technology.

Finally, using the Stanford IP litigation database (www.lexmachina.org), we generate a dummy variable - litigated - which gives 1 if the patent has been cited in at least one law suit in the database.

\section{II.2 Descriptive statistics}

In this section, we will use the comprehensive database to provide descriptive statistics on the predictions of the theory on cumulative innovation. The results in table 2 are consistent with many arguments drawn from the literature on cumulative innovation: indeed, in line with the hypothesis that the cumulative nature of innovation in complex industries drives up citation

\footnotetext{
${ }^{8}$ See von Graevenitz, Wagner and Harhoff (2009) or Cohen, Nelson and Walsh (2000)
} 
rates, both backward and forward cite rates are significantly higher in the complex than in the non-complex random sample, whereas the scores for claims are not significantly different, and family size is much bigger in the discrete sample. Furthermore, we confirm previous findings that the litigation rate is indeed higher in complex than in discrete industries (1.4 compared to $1 \%$ ). This could hint to the fact that patents are indeed used in a slightly more "litigious" way in complex industries, and corroborates the argument that patents generate value in a different way from complex to discrete technological fields. Furthermore, higher renewal rates on complex technology patents also provide evidence that less patents are of low value to their owners in complex technologies.

Citation rates are even much higher in the sample of essential patents than among random complex technology patents. On the one hand, this could indicate that patents in this sample are even more cumulative than the average of their technological field. On the other hand, as these patents score high also on all the other quality indicators and on renewal and litigation rate, the high citation rate seems at least partly to be driven by a selection effect: essential patents are highly cited, because they are better than average patents from their technological field. In the remainder of the analysis, we will have to control for this selection effect, as we want to rule out that results that we attribute to cumulativeness result from selection.

Furthermore, these descriptive statistics call for a cautious use of quality indicators when comparing the different samples. Consistently with the argument that claims are driven up in cumulative innovation in order to maximize the chances of blocking successive research paths, we find the average number of claims to be higher for essential patents. Furthermore, family size is bigger on average in the sample of essential patents, which provides some support to the argument that numerous patents are filed on single inventions in order to inflate patent portfolios. Finally, as discussed, high citation rates among essential patents could result from the fact that these patents relate to technological fields where the general propensity to patent is high, which results in prior art protected by a higher number of patents. Before interpreting the indicator scores in terms of quality, we therefore turn to an extensive factor analysis to rule out that such noise on single indicators affects our results.

\begin{tabular}{c|cc|cc|cc|cc}
\hline & \multicolumn{2}{|c|}{ Complete sample } & \multicolumn{2}{|c|}{ Discrete technologies } & \multicolumn{2}{c|}{$\begin{array}{c}\text { Complex non standardized } \\
\text { technologies }\end{array}$} & $\begin{array}{c}\text { Complex standardized } \\
\text { technologies }\end{array}$ \\
\hline & Mean & $\begin{array}{c}\text { Standard } \\
\text { deviation }\end{array}$ & Mean & $\begin{array}{c}\text { Standard } \\
\text { deviation }\end{array}$ & Mean & $\begin{array}{c}\text { Standard } \\
\text { deviation }\end{array}$ & Mean & $\begin{array}{c}\text { Standard } \\
\text { deviation }\end{array}$ \\
\hline $\begin{array}{c}\text { Allnscites } \\
\text { Backward }\end{array}$ & 23,35 & 42,76 & 8,58 & 15,42 & 20,93 & 36,66 & 40,15 & 57,86 \\
cites & 9,30 & 14,12 & 7,28 & 9,67 & 8,87 & 15,38 & 11,72 & 16,18 \\
Claims & 16,85 & 15,09 & 15,19 & 14,07 & 15,77 & 12,92 & 19,66 & 17,54 \\
Family size & 15,66 & 46,33 & 13,64 & 40,15 & 6,51 & 17,88 & 24,75 & 62,67 \\
Generality & 0,35 & 0,37 & 0,22 & 0,34 & 0,39 & 0,37 & 0,43 & 0,35 \\
Originality & 0,23 & 0,24 & 0,14 & 0,22 & 0,26 & 0,25 & 0,25 & 0,22 \\
Renewal at 8 & 0,73 & 0,44 & 0,59 & 0,49 & 0,73 & 0,44 & 0,95 & 0,21 \\
Renewal at 12 & 0,57 & 0,50 & 0,37 & 0,48 & 0,55 & 0,50 & 0,92 & 0,27 \\
Litigated & 0,03 & 0,17 & 0,01 & 0,10 & 0,01 & 0,12 & 0,07 & 0,25 \\
\hline
\end{tabular}

Table 2 : Descriptive statistics of indicators 


\section{Are indicators consistent for different technologies: the principal factor analysis}

The aim of this part is to compare the stability of indicators among different technological sectors. In order to study the consistence of the indicators, we will use a factor analysis. Factor analysis is a way to describe variability among observed variables through a smaller number of underlying variables called factors. Factor analysis is concerned with the common covariance of the variables and estimates how much of the variability is due to common factors.

Thus, the factor analysis uses a large number of observations and reveals common patterns underlying the variables. For instance, factor analysis is a method regularly used in political sciences to highlight the unobserved political convictions of surveyed people using their expressed opinion on various societal problems. In economics, factor analysis is used when capturing a common phenomenon is more interesting than analyzing individual variables. For example, it is a method used for a very long time to capture the growth phenomenon of a country ${ }^{9}$. Lanjouw and Schankerman (2004) first used the principal factor analysis to identify an overall patent quality factor through four indicators.

In this part we will use the factor analysis for our three samples: discrete, complex standardized and complex non standardized technologies. The objective is to study the stability of the different indicators according to the technological sectors and see if a common pattern exists.

We first run a factor on four indicators frequently used to assess the "quality" of a patent namely the number of forward cites, the number of claims, the number of backward cites and the family size of the patent. We only make the comparison for the discrete and complex samples in order to revisit precedent results on the subject (Lanjouw \& Schankerman (2004)). Our results on this first factor analysis (presented in annex 1) are very closed to the previous results using the same method. We highlight that the impact of forward cites on the common factor 1 is more important for non complex technologies than for complex technologies. Inversely, the impact of the number of claims is more important in the case of complex technologies. We can also highlight that the common covariance explained by factor 1 is less important in the case of complex technologies.

We then perform the same principal factor analysis using two new indicators: the originality and the generality of the patent. The generality and originality, measured by the number of forward or backward cites between the patent and patents from other technological classes, can get an idea of the patents' interest for broader technological applications (Hall \& all., 2001). We run this factor analysis on our three samples to compare the stability of the indicators according to the technological sectors. The following table summarizes the loadings for each sample.

\footnotetext{
${ }^{9}$ For more information on applying these method to the data on a countrys' growth, see Adelman I. and Taft Morris C., «A Factor Analysis of the Interrelationship Between Social and Political Variables and Per Capita Gross National Product », The Quarterly Journal of Economics, Vol. 79, No. 4 (Nov., 1965), pp. 555-578
} 


\begin{tabular}{|l|c|c|c|c|c|c|}
\hline & \multicolumn{2}{|c|}{ Discrete technologies } & $\begin{array}{c}\text { Complex non standardized } \\
\text { technologies }\end{array}$ & \multicolumn{2}{c|}{$\begin{array}{c}\text { Complex Standardized } \\
\text { Technologies }\end{array}$} \\
\hline & Factor 1 & Factor 2 & Factor 1 & Factor 2 & Factor 1 & Factor 2 \\
\hline Variance & 0.48807 & 0.24936 & 0.26113 & 0.24636 & 0.47470 & 0.28419 \\
\hline $\begin{array}{l}\text { Forward } \\
\text { cites }\end{array}$ & 0.4532 & 0.0021 & 0.3029 & 0.1377 & 0.2139 & 0.3903 \\
\hline $\begin{array}{l}\text { Backward } \\
\text { cites }\end{array}$ & 0.3549 & 0.0762 & 0.4036 & -0.0143 & -0.0722 & 0.0685 \\
\hline Claims & 0.2383 & -0.0049 & 0.4197 & 0.0469 & 0.0563 & 0.3745 \\
\hline Originality & -0.0794 & 0.3629 & -0.0286 & 0.3467 & 0.4441 & 0.0759 \\
\hline Generality & 0.0370 & 0.3662 & 0.1113 & 0.3276 & 0.3828 & 0.1426 \\
\hline Family size & 0.4174 & -0.0950 & 0.2102 & 0.0289 & -0.0677 & 0.1463 \\
\hline $\begin{array}{l}\text { Number of } \\
\text { observations }\end{array}$ & 3139 & \multicolumn{3}{|c|}{3004} & & 3191 \\
\hline
\end{tabular}

Table 3 : Loadings factor analysis six indicators

Table 3 is useful to emphasize some conclusions on the stability of indicators. The first result is that there are two main factors underlying these indicators. A first factor is mainly correlated to the number of forward cites, claims and to some extent backward cites and family size. This first factor has already been discussed in the literature (Lanjouw \& Schankerman, 2004) and named "quality". We will thus continue to call it this way. Table also stresses the existence of a second factor, having an important impact on the indicators common covariance, for both the complete and discrete samples. This second factor is mainly linked to the generality and the originality of the patent. For complex patents (as opposed to the discrete sample), this second factor also has significant loadings on the citation indicators. A plausible interpretation would be that this factor discriminates between fundamental and incremental innovations; which could be the reason why it is particularly linked to the generality and originality of the patent but also with the number of cites in the case of complex technologies. According to the existing literature (Trajtenberg, Henderson and Jaffe, 1997), we will use the denomination "basicness factor". For the complex standardized sample, this basicness factor significantly drives the common covariance of the indicators. It becomes the most important factor for this sample and the quality factor is overshadowed.

In spite of the presence of a second factor that is especially important in samples of cumulative patents, we identify a quality factor that is roughly consistent throughout the samples. In all three samples, the quality factor is driven by a positive correlation between forward cites, claims and family size. Nevertheless, the loadings of indicators are slightly different between complex and discrete technologies. The number of claims seems to have more impact than the number of forward cites on the quality factor for the complex sample. It is exactly the opposite in the case of discrete technologies, where the most important indicator is the number of forward cites. Another point on the loadings of the quality factor is the greater importance of the backward cites for the complex non standardized sample than for the discrete sample. This indicator is often considered as a way to assess the patent holder investment in the patent refinement. It could thus be a way to discriminate in complex technologies between patents resulting from less significant innovation effort. Therefore it is interesting to note that this indicator is strongly linked to the first factor "quality" in the case of complex non standardized technologies. For the complex standardized sample, the quality factor remains the same except for the backward cites. Indeed, backward citations play no role in the definition of the factor. This strengthens our intuition that backward citations are 
mainly useful for screening out low quality patents. We are confident that in our sample of essential patents the share of low quality patents is far below average.

Another important difference is the variance explained by the quality factor between the complex and discrete sample. Indeed, we can underline that this quality factor explains almost fifty percent of the covariance of the indicators for the discrete sample. However, in the complex samples, this factor only explains one fourth of the common covariance of the indicators.

For the basicness factor, we use data on the timing of declaration or introduction of patents into standard setting organizations and patent pools to corroborate our interpretation. We created two new variables, founding patent pool, which equals 1 if the patent is a pool founding patent and founding_patent_sso which equals 1 if the patent was disclosed before the average age of patent disclosure to the respective standard. These variables allow us to discriminate between fundamental and incremental innovations. The underlying assumption is that founding patents of a pool or a standardization project are more fundamental. We run a regression with the two variables founding patent pool and founding_patent_sso as explained variable and the factors highlighted in this section as the explanatory variables. The results are presented in table 6 (appendix 4). They show that both factors are related to being a founding patent. The results on the basicness factor stress that being a founding patent of a pool or a standardization project is significantly linked to a high score on the factor. This could confirm our interpretation that this factor discriminates between fundamental and incremental innovations. The quality factor is also significantly associated with the likelihood of being a founding patent. This confirms that founding patents of a standardization process are of better quality than patents disclosed later in the process (see Baron \& Delcamp, 2010).

To sum up our main conclusions, we can say that the factor analysis underlines the existence of two factors driving the common covariance of the indicators. The first one, mainly linked to the traditional indicators of quality has already been studied in the literature. The second one is mainly driven by the generality and originality of the patent. We call it the basicness or fundamentality factor and give some evidence corroborating our interpretation. For the complex standardized sample, this basicness factor explains almost half of the common covariance of the indicators. The quality factor seems to remain stable (with some minor changes on claims and forward cites) across our three different samples except for the importance of the backward cites. Indeed, the weight on this indicator on the quality factor is important and stable for both our discrete and complex non standardized sample but does not have any importance for the complex standardized sample.

In the next section, we will look at the ability of these factors especially the quality one to predict the private value of the patent. In order to assess the private value of a patent, we will use data on renewals and litigations. To take into account the finding on the unstability of backward cites on the quality factor, we will use a common quality factor compound of forward cites, claims and family size.

\section{The link between patent quality and private value in discrete and cumulative innovation}

As discussed in part I, we expect that the link between indicators of patent quality and patent value is weakened when patents are cumulative. The literature identifies complex 
technologies where innovation is in general thought to be more cumulative, for instance electronics and telecommunication. Even though the question has never been explicitly addressed, several arguments in the empirical literature point to a weaker link between patent quality and patent value in some classes identified as complex. We will test the theory of a significant difference as to the private value of patents and its link to patent quality between complex and discrete technology patents. Specifically, we will estimate the value of patents in an ordered logistic regression estimation of patent renewals. Comparing samples of complex and discrete technology patents, we will test whether the common patent quality factor is less explanatory of patent value in complex technologies. We also analyze whether patents in complex technologies are more valuable than patents in discrete technologies of the same patent quality.

Second, we test more directly for the effects of cumulative innovation by introducing a sample of patents declared essential to technological standards. As explained above, standardization is a procedure to ensure compatibility between complementary technologies. It is therefore by definition part of a cumulative innovation effort. Standardization can also be analyzed as a strategy of firms to navigate through the patent thicket. Essential patents are those patents that are necessarily infringed by any implementation of the standard. The blocking potential of essential patents is therefore extended to the whole standard. We have thus argued that if cumulative innovation weakens the link between patent quality and patent value, this should clearly be seen in the case of essential patents. Therefore we test directly whether patent quality contributes less to patent value in the case of essential patents, and whether essential patents are more valuable than non-essential patents of the same quality.

We thus estimate the following baseline equation:

$V=\alpha \cdot Q+C+\delta \cdot X+\varepsilon$

where $\mathrm{V}$ represents patent value, measured through an ordered logistic regression of the probability of patent renewal. $\mathrm{Q}$ represents patent quality, measured by the quality factor established in part III.1. $\mathrm{X}$ is a vector of control variables, including application year and assignee dummies. $\mathrm{C}$ is a constant and $\varepsilon$ is a stochastic error term.

We introduce dummies for complex technologies and essential patents. Both dummies are interacted with patent quality.

$$
V=\alpha \cdot Q+[\beta \cdot P C+\gamma \cdot P c \times Q]+\left[\beta^{r} \cdot P s+\gamma^{\prime} \cdot P s \times Q\right]+\delta \cdot X+C+\varepsilon
$$

\section{Hypothesis 1:}

$\beta>0$ and $\beta^{\prime}>0$, there is a premium for patents in cumulative innovation, therefore patents in complex technologies (respectively essential patents) are more valuable than patents of the same quality in discrete innovation 


\section{Hypothesis 2:}

$\gamma<0$ and $\gamma^{\prime}<0$, patent quality is less important for patent value in cumulative innovation.

\begin{tabular}{|c|c|c|}
\hline & $\begin{array}{c}\text { Ordered logistic regression } \\
\text { renewals }\end{array}$ & $\begin{array}{c}\text { Ordered logistic regression } \\
\text { renewals }\end{array}$ \\
\hline Quality factor & $\begin{array}{l}1.1307099^{* \star *} \\
(0,259)\end{array}$ & $\begin{array}{c}1.1559108^{* * *} \\
(0,264)\end{array}$ \\
\hline Basicness factor & & $\begin{array}{c}-.05613295 \\
(0,155)\end{array}$ \\
\hline Dummy standardized & $\begin{array}{l}1.7132462^{* * *} \\
\quad(0,280)\end{array}$ & $\begin{array}{l}1.744291^{\star \star *} \\
(0,335)\end{array}$ \\
\hline Dummy complex & $\begin{array}{l}.56856639^{\star \star *} \\
(0,128)\end{array}$ & $\begin{array}{c}.65117365^{\star * *} \\
(0,139)\end{array}$ \\
\hline $\begin{array}{l}\text { Interaction } \\
\text { Quality_standardized }\end{array}$ & $\begin{array}{c}-1.4333137^{* *} \\
(0,540)\end{array}$ & $\begin{array}{c}-1.4228873^{*} \\
(0,594)\end{array}$ \\
\hline $\begin{array}{l}\text { Interaction } \\
\text { Quality_complex }\end{array}$ & $\begin{array}{c}.48543312 \\
(0,349)\end{array}$ & $\begin{array}{c}.59521786 \\
(0,361)\end{array}$ \\
\hline $\begin{array}{l}\text { Interaction } \\
\text { Basicness_standardized }\end{array}$ & & $\begin{array}{c}-.35715422 \\
(0,738)\end{array}$ \\
\hline $\begin{array}{l}\text { Interaction } \\
\text { Basicness_complex }\end{array}$ & & $\begin{array}{c}-.24520092 \\
(0,235)\end{array}$ \\
\hline Control Application year & $\mathrm{Y}$ & Y \\
\hline Control Assignee & $\mathrm{Y}$ & $Y$ \\
\hline Number of obs & 1637 & 1637 \\
\hline Wald chi2 & 260.31 & 258.76 \\
\hline Prob > chi2 & 0.0000 & 0.0000 \\
\hline Pseudo R2 & 0.0859 & 0.0870 \\
\hline
\end{tabular}

Table 4: The link between quality and value for cumulative and discrete innovation

Table 4 allows underlining a couple of results. First of all, patent quality is an important part of the definition of patent value. The parameter for the quality_factor variable is positive and significant for our two models. The link between value and a compound factor of quality is verified in our case. 
Hypothesis 1 is also verified, there is a premium for patents in cumulative innovations. Thus patents in complex technologies (and within complex technologies, essential patents) are more valuable than patents of the same quality and presenting the same characteristics in discrete technologies. Hypothesis 2 is verified for essential patents, the parameter interaction_quality_standardized is negative and significant. Therefore, the quality takes a smaller share in the definition of patent value for cumulative innovation (i.e. the link between quality and value is less obvious for cumulative innovation). But hypothesis 2 is not verified for the overall complex sample. Thus, the quality factor predicts renewal in discrete and complex, but not in standardized samples. We verify that this is not due to a selection effect. Indeed, one could argue that quality indicators are less informative of patent value in a sample of essential patents, as all these patents are selected and their quality and value is above average. Nevertheless, we control for selection effects by excluding all patents from the analysis that have never been renewed, by restricting the samples to patents that have been litigated, by dropping all patents from the sample that that have a quality factor score above average, and by introducing the square of the quality factor as a control variable to control for non-linear effects. There is no evidence for non-linear effects of patent quality on patent value throughout the sample, and our results hold under all the different control strategies (The results are available upon request from the authors). As we can rule out that our results are driven by a selection effect, it is thus clearly cumulativeness that alters the way how patents generate value. Nevertheless, this cumulativeness is rather unrelated to technological classes, as random patents from exactly the same technology classes as the essential patents do not exhibit any weakened link between patent quality and value.

Table 7 (appendix 5) allows refining the previous results. We run the same regression as in table 4 for each quality indicator individually. For model 1, we use in the same regression all the quality indicators together as explanatory variable. The parameters therefore allow assessing the indicators' impact everything else equal. Model 2 reports the parameters for each indicator used individually as explanatory variable. We present this model because indicators are more often used individually especially by policymakers or patent experts. In order to check the robustness to the way how we measure patent value, we also introduce patent litigation as an alternative indicator.

Table 7 confirms that quality indicators, especially forward cites, claims and family size are good predictors of patent value (measured by litigation or renewal) for discrete and complex non-standardized technologies. The number of claims works well for predicting the value of complex non-standardized patents but not for discrete technologies. This confirms our previous results on the difference in the quality factor between complex and discrete technologies: the number of claims becomes more informative than the forward cites for complex technologies. The main result is that no indicator works for predicting the patent value for complex standardized technologies. This is in line with our hypothesis that cumulativeness disrupts the link between quality and value. The most important difference is not between complex and discrete technological classes, but within complex technologies.

\section{Implications for policy and research methodology}

We have demonstrated a very significant and robust relationship between patent quality and value. Nevertheless, this robust relationship completely disappears in highly cumulative 
innovation, as demonstrated using a sample of patents declared essential to technological standards. While these patents are clearly better on average and more valuable than the control patents, quality plays no role for explaining differences in patent value inside the sample.

The lesson to be drawn from this insight is twofold: on the one hand, our findings allow revisiting the patent portfolio theory for cumulative innovation. As to the portfolio theory, patents are valuable as such, independently of their quality or any other measurable patent characteristics. This has strong implications for patent filing incentives and innovation strategies. The primary determinant of patent value is the capacity of blocking other patents. We have shown in our empirical work that patents with blocking power over a standard are much more valuable than other patents in the same technological field of comparable quality. Furthermore, among these essential patents with blocking power over a standard, patent quality is no longer a determinant of patent value. Therefore, patent holders have incentives not to pursue patent quality, as long as they can achieve blocking power over the standard. This finding provides support to those who see the surge in essential patents with some worries. However, we also showed that essential patents are still much better in terms of any quality indicator than control patents, so that we can conclude that the selection mechanism at work during standardization is not defunct.

On the other hand, our results suggest that the link between patent quality and value is quite robust over technology classes. This means that while cumulative innovation alters the way how patents generate value in relatively narrow, highly cumulative sectors identified through formal standardization, this does not affect the relevant technology classes as a whole. Indeed, our sample of complex technology patents drawn from exactly the same classes as the essential patents does not exhibit a weakened link between patent quality and value. This suggests that the effects of cumulative innovation are important only in narrow yet highly relevant technological fields.

This latter finding is important for appreciating the implications for research methodology. Indeed, we find no evidence that patent quality indicators are less informative in complex than in discrete technological classes. Patent quality predicts renewal decisions and litigation even more accurately in our sample of (randomly chosen) complex technology patents. Comparing single indicator, we confirm previous findings that claims are a more informative indicator than forward citations when studying complex technologies.

In turn, the indicators behave very differently in the sample of essential patents. First, none of the studied indicators predicts patent renewals or litigation with any accuracy. We conclude that it is erroneous to use indicators of patent quality such as forward citations or claims to approximate the value of essential patents. Second, the indicators seem to be mainly driven by an underlying factor that is different from patent "quality" or importance. We have interpreted this factor as "basicness" of the patent and highlighted some evidence for this interpretation.

We thus find that observable patent characteristics are not informative of patent value in the case of cumulative innovation and that the characteristics of these patents are driven by factors that are orthogonal to patent quality or significance. This is bad news, as it implies that indicators of patent quality or importance function the worse where the industry most needs them. Indeed, pooling of patents, cross licensing schemes and other clearing mechanisms widely practiced for highly relevant cumulative innovations are dependent upon objective and clear criteria for establishing royalty sharing rates. Our analysis reveals that at least the candidate indicators most commonly used in the literature are of no use to this respect. 


\section{REFERENCES}

- Baron J. and Delcamp H. (2010), Strategic inputs into patent pools, Working paper

- Cohen W., Nelson R. and Walsh J. (2000), Protecting Their Intellectual Assets: Appropriability Conditions and Why U.S. Manufacturing Firms Patent (or Not), NBER Working paper

- Giummo J. (2003), Should All Patentable Inventions Receive Equal Protection? Identifying the Sources of Heterogeneity in Patent Value, Discussion Paper, University of California, Berkeley

- Griliches Z. (1990), Patent statistics as economic indicators : a survey, Journal of economic literature, Vol. 28, $\mathrm{N}^{\circ} 4$, pp.1661-1707

- Hall B. H., Jaffe A., Trajtenberg M. (2005), Market value and patent citations, RAND Journal of Economics, Vol. 36, pp. 16-38

- Hall, B. H., A. B. Jaffe, and M. Trajtenberg (2001), The NBER Patent Citation Data File: Lessons, Insights and Methodological Tools, NBER Working Paper 8498

- Hall, B. H., Ziedonis, R.H. The Patent Paradox Revisited: Determinants of Patenting in the U.S. Semiconductor Industry, 1980-94, Rand Journal of Economics, Vol. 32

- Harhoff D., Narin F., Scherer F.M., Vopel K. (1999), Citation frequency and the value of patented inventions, The Review of Economics and Statistics, Vol. 81, pp. $511-515$

- Harhoff D. and Wagner S. (2009), The Duration of Patent Examination at the European Patent Office, Management Science, Volume 55, Issue 12, Pages: 19691984 
- Kohler F., Blind K. and Thumm N. (2009), Keep 'Em In, Make 'Em Fit : An Analysis of Patent Filing Behaviour for Essential Patents in Standards, Working Paper

- Kusunoki K., Nonaka I. and Nagata A. (1998), Organizational Capabilities in Product Development of Japanese Firms: a Conceptual Framework and Empirical Findings, Organization Science, Volume 9, Issue 6

- Lanjouw, J. and Schankerman, M. (1999), The quality of ideas: measuring innovation with multiple indicators, NBER Working Paper

- Lanjouw J. and Schankerman M. (2004), Patent quality and research productivity: measuring innovation with multiple indicators, Economic journal, 114 (495). pp. 441 465

- Lanjouw J. and Schankerman M. (2004), Protecting intellectual property rights: are small firms handicapped?, The journal of law and economics, 47 (1). pp. 45-74.

- Lerner J. (2008), The Litigation of Financial Innovations, NBER Working Paper No. W14324

- Levin R.C., Klevorick A.K., Nelson R.R., Winter S.G., Gilbert R. and Griliches Z. (1987), Appropriating the Returns from Industrial Research and Development, Brookings Papers on Economic Activity, No. 3, Special Issue On Microeconomics, pp. $783-831$

- $\quad$ Liu, K., Arthurs, J., Cullen, J. \& Alexander, R. (2008), Internal sequential innovations: How does interrelatedness affect patent renewal?, Research Policy, 37, issue 5, pp. 946-953

- Merges R. P. and Nelson R. (1990), On the Complex Economics of Patent Scope, Columbia Law Review, Vol. 90, No. 4, pp. 839-916 
- Nagaoka,, S. (2005), Patent quality, cumulative innovation and market value: Evidence from Japanese firm level panel data, IIR Working Paper 05-06, Institute of Innovation Research, Hitotsubashi University

- Parchomovsky, G. \& Polk Wagner, R. (2005), Patent Portfolios, University of Pennsylvania Law Review

- Popp D., Juhl T. and Johnson D. (2004), Time In Purgatory: Examining the Grant Lag for U.S. Patent a pplications, Topics in Economic Analysis \& Policy: Vol. 4 : Iss. 1, Article 29

- Rysman M., Simcoe T. (2008), Patents and the Performance of Voluntary Standard Setting Organizations, Management Science, Vol. 54, N 11, pp. 1920-1934

- Salant, D. (2009), Formulas for Fair, Reasonable, and Non-Discriminatory Royalty Determination, International Journal of IT Standards and Standardization Research, Volume 7, Issue 1, pp. 66-75

- Simcoe T., Graham S. and Feldman M. (2009), Competing on Standards? Entrepreneurship, Intellectual Property, and Platform Technologies, Journal of Economics \& Management Strategy, Vol. 18, Issue 3, pp. 775-816

- Swanson, D. \& Baumol W. (2005), Reasonable and Nondiscriminatory (RAND) Royalties, Standards Selection, and Control of Market Power, Antitrust Law Journal, Volume 73

- Thomas, P. (1999), The Effect of Technological Impact upon Patent Renewal Decisions, Technology Analysis \& Strategic Management, Volume 11(2), 181-197.

- Trajtenberg, M. (1990), A Penny for Your Quotes: Patent Citations and the Value of Innovations, The RAND Journal of Economics, Vol. 21, No. 1, pp. 172-187 
- Trajtenberg, M. (1990), Economic Analysis of Product Innovation: The Case of CT Scanners (Harvard Economic Studies), Harvard University Press

- Trajtenberg; M., Henderson, R. \& Jaffe, A. (1997), University versus Corporate Patents: A Window on the Basicness of Invention, Economics of Innovation and New Technology, Volume 55, Issue 1, pp. 19 - 50

- Von Graevenitz, G., Wagner, S. \& Harhoff, D. (2009), How to measure patent thickets: a novel approach, Discussion Papers in Business Administration 10962, University of Munich, Munich School of Management 


\section{$\underline{\text { Appendix } 1}$}

\section{The factor analysis of four indicators}

The following table summarizes the results of a principal factor analysis of the four main indicators of patent quality used by Lanjouw \& Schankerman.

\begin{tabular}{lcccc}
\hline & \multicolumn{2}{c}{ Discrete technologies } & \multicolumn{2}{c}{ Complex technologies } \\
\hline Variance & 0.52903 & 0.07807 & 0.31715 & 0.23077 \\
\hline allnscites & 0.4456 & 0.1267 & 0.3053 & 0.1541 \\
cmade & 0.3543 & 0.1614 & 0.2875 & 0.3087 \\
claims & 0.2311 & 0.1825 & 0.3462 & 0.1783 \\
familysize & 0.3893 & 0.0518 & 0.1464 & 0.2827 \\
\hline Number of observations & \multicolumn{2}{c}{3139} \\
\hline
\end{tabular}

Table 5: Factor analysis four indicators 


\section{Appendix 2}

\section{List non complex technology classes}

19 Textiles: Fiber Preparation

26 Textiles: Cloth Finishing

28 Textiles: Manufacturing

29 Metal Working

38 Textiles: Ironing or Smoothing

44 Fuel and Related Compositions

57 Textiles: Spinning, Twisting, and Twining

66 Textiles: Knitting

68 Textiles: Fluid Treating Apparatus

71 Chemistry: Fertilizers

Specialized Metallurgical Processes, Compositions for Use Therein, Consolidated Metal

75 Powder Compositions, and Loose Metal Particulate Mixtures

76 Metal Tools and Implements, Making

87 Textiles: Braiding, Netting, and Lace Making

99 Foods and Beverages: Apparatus

100 Presses

101 Printing

135 Tent, Canopy, Umbrella, or Cane

139 Textiles: Weaving

148 Metal Treatment

162 Paper Making and Fiber Liberation

164 Metal Founding

228 Metal Fusion Bonding

229 Envelopes, Wrappers, and Paperboard Boxes

423 Chemistry of Inorganic Compounds

424 Drug, Bio-Affecting and Body Treating Compositions

429 Chemistry: Electrical Current Producing Apparatus, Product, and Process

435 Chemistry: Molecular Biology and Microbiology

436 Chemistry: Analytical and Immunological Testing

514 Drug, Bio-Affecting and Body Treating Compositions

518 Chemistry: Fischer-Tropsch Processes; or Purification or Recovery of Products Thereof

585 Chemistry of Hydrocarbon Compounds 


\section{List technology classes of standardized patents}

Class Description of the class

$\begin{array}{rr}\text { Discrete } & \text { Complex } \\ 1 & 0\end{array}$

8 Bleaching and Dyeing; Treatment of Textiles and Fibers

16 Miscellaneous Hardware

29 Metal Working

36 Boots, Shoes, and Leggings

40 Card, Picture, or Sign Exhibiting

73 Measuring and Testing

75 Specialized Metallurgical Processes

84 Music

105 Railway Rolling Stock

119 Animal Husbandry

169 Fire Extinguishers

174 Electricity: Conductors and Insulators

178 Telegraphy

188 Brakes

211 Supports: Racks

235 Registers

250 Radiant Energy

257 Active Solid-State Devices (e.g., Transistors, Solid-State Diodes)

264 Plastic and Nonmetallic Article Shaping or Treating: Processes

283 Printed Matter

315 Electric Lamp and Discharge Devices: Systems

324 Electricity: Measuring and Testing

326 Electronic Digital Logic Circuitry

327 Miscellaneous Active Electrical Nonlinear Devices, Circuits, and Systems

329 Demodulators

330 Amplifiers

331 Oscillators

332 Modulators

333 Wave Transmission Lines and Networks

335 Electricity: Magnetically Operated Switches, Magnets, and Electromagnets

340 Communications: Electrical

341 Coded Data Generation or Conversion

342 Communications: Directive Radio Wave Systems and Devices (e.g., Radar)

343 Communications: Radio Wave Antennas

345 Computer Graphics Processing, Operator Interface Processing ...

346 Recorders

347 Incremental Printing of Symbolic Information

348 Television

351 Optics: Eye Examining, Vision Testing and Correcting

358 Facsimile and Static Presentation Processing

359 Optics: Systems (Including Communication) and Elements

360 Dynamic Magnetic Information Storage or Retrieval

361 Electricity: Electrical Systems and Devices

362 Illumination

365 Static Information Storage and Retrieval

367 Communications, Electrical: Acoustic Wave Systems and Devices

369 Dynamic Information Storage or Retrieval

370 Multiplex Communications

375 Pulse or Digital Communications

379 Telephonic Communications

380 Cryptography

381 Electrical Audio Signal Processing Systems and Devices

382 Image Analysis

385 Optical Waveguides

386 Television Signal Processing for Dynamic Recording or Reproducing

0

0

0

1

2

0

0

0

0

0

3

1

0

0 
395 Information Processing System Organization

401 Coating Implements with Material Supply

423 Chemistry of Inorganic Compounds

428 Stock Material or Miscellaneous Articles

430 Radiation Imagery Chemistry: Process, Composition, or Product Thereof

434 Education and Demonstration

435 Chemistry: Molecular Biology and Microbiology

436 Chemistry: Analytical and Immunological Testing

438 Semiconductor Device Manufacturing: Process

439 Electrical Connectors

455 Telecommunications

473 Games Using Tangible Projectile

514 Drug, Bio-Affecting and Body Treating Compositions

524 Synthetic Resins or Natural Rubbers -- Part of the Class 520 Series

568 Organic Compounds -- Part of the Class 532-570 Series

604 Surgery

606 Surgery

700 Data Processing: Generic Control Systems or Specific Applications

701 Data Processing: Vehicles, Navigation, and Relative Location

702 Data Processing: Measuring, Calibrating, or Testing

704 Data Processing: Linguistics, Audio Compression/Decompression

705 Data Processing: Financial, Business Practice, Management

707 Data Processing: Database and File Management, Data Structures

708 Electrical Computers: Arithmetic Processing and Calculating

709 Electrical Computers and Digital Processing Systems: Multiple Computer

710 Electrical Computers and Digital Data Processing Systems: Input/Output

711 Electrical Computers and Digital Processing Systems: Memory

713 Electrical Computers and Digital Processing Systems: Support

714 Error Detection/Correction and Fault Detection/Recovery 


\section{$\underline{\text { Apendix } 3}$}

\section{List of pools}

- 1394

- DVD 6C

- MPEG 2

- MPEG 4 Systems

- MPEG 4 Visual

- AVC

- DVB-T

\section{$\underline{\text { List of Standard Setting Organizations }}$}

- American National Standard Institute

- Alliance for Telecommunications Industry Standards

- European Telecommunications Standards Institute

- Institute for Electrical and Electronic Engineering

- Internet Engineering Task Force,

- International Organization for Standards International Electrotechnical Commission

- International Telecommunications Union

- Telecommunications Industry Association 


\section{Appendix 4}

\begin{tabular}{|c|c|c|}
\hline Probit & Founding patent SSO & Founding patent pool \\
\hline Fundamentality factor & $\begin{array}{c}.24171685^{\star * *} \\
(0.127)\end{array}$ & $\begin{array}{c}0.25693^{*} \\
(0.127)\end{array}$ \\
\hline Quality factor & $\begin{array}{c}.5337134^{* * *} \\
(0.196)\end{array}$ & $\begin{array}{l}0.50440^{* *} \\
(0.196)\end{array}$ \\
\hline Age effect & $\begin{array}{l}.08695842^{*} \\
(0.094)\end{array}$ & $\begin{array}{l}0.16499 \\
(0.094)\end{array}$ \\
\hline $\begin{array}{l}\text { Dummy Assignee control } \\
\text { cons }\end{array}$ & $\begin{array}{c}Y \\
-173.91463^{*} \\
(187.164)\end{array}$ & $\begin{array}{c}Y \\
-327.86429 \\
(187.164)\end{array}$ \\
\hline Number of obs & 2601 & 369 \\
\hline Wald chi2(22) & 217.33 & 86.89 \\
\hline Prob > chi2 & 0 & 0 \\
\hline \multicolumn{3}{|c|}{$\begin{array}{l}\text { legend: }{ }^{*} p<0.05 ;{ }^{* *} p<0.01 ;{ }^{* * *} p<0.001 \\
\text { Robust standard erros in parentheses }\end{array}$} \\
\hline
\end{tabular}

Table 6: Interpretation basicness factor 


\section{Appendix 5}

\begin{tabular}{|c|c|c|c|c|c|c|c|c|c|c|c|c|}
\hline & \multicolumn{4}{|c|}{ Discrete technologies } & \multicolumn{4}{|c|}{ Complex non standardized technologies } & \multicolumn{4}{|c|}{ Standardized Technologies } \\
\hline & \multicolumn{2}{|c|}{ Litigated } & \multicolumn{2}{|c|}{ Renewed at 8} & \multicolumn{2}{|c|}{ Litigated } & \multicolumn{2}{|c|}{ Renewed at 8} & \multicolumn{2}{|c|}{ Litigated } & \multicolumn{2}{|c|}{ Renewed at 8} \\
\hline & Model 1 & Model 2 & Model 1 & Model 2 & Model 1 & Model 2 & Model 1 & Model 2 & Model 1 & Model 2 & Model 1 & Model 2 \\
\hline $\begin{array}{l}\text { Forward } \\
\text { cites }\end{array}$ & $\begin{array}{l}0.008^{*} \\
(0.003)\end{array}$ & $\begin{array}{c}0.009 * * * \\
(0.0293)\end{array}$ & $\begin{array}{c}0.007 * * \\
(0.002)\end{array}$ & $\begin{array}{c}0.011^{* * * *} \\
(0.0120)\end{array}$ & $\begin{array}{c}0,005 * * * \\
(0.001)\end{array}$ & $\begin{array}{c}0.005^{* * * *} \\
(0.0636)\end{array}$ & $0,006 * * *$ & $\begin{array}{l}0.005 * * \\
(0.0154)\end{array}$ & $\begin{array}{l}-0,001 \\
(0.001)\end{array}$ & $\begin{array}{c}0.001 \\
(0.0179)\end{array}$ & $\begin{array}{l}-0,001 \\
(0.002)\end{array}$ & $\begin{array}{c}0.001 \\
(0.0062)\end{array}$ \\
\hline $\begin{array}{l}\text { Backward } \\
\text { cites }\end{array}$ & $\begin{array}{l}-0.013 \\
(0.008)\end{array}$ & $\begin{array}{c}-0.004 \\
(0.0105)\end{array}$ & $\begin{array}{l}-0.005 \\
(0.003)\end{array}$ & $\begin{array}{c}0.003 \\
(0.0003)\end{array}$ & $\begin{array}{l}0,010^{*} \\
(0.004)\end{array}$ & $\begin{array}{l}0.008^{* *} \\
(0.0382)\end{array}$ & $-0,004$ & $\begin{array}{c}0.002 \\
(0.0003)\end{array}$ & $\begin{array}{l}-0,003 \\
(0.004)\end{array}$ & $\begin{array}{c}0.001 \\
(0.0029)\end{array}$ & $\begin{array}{l}-0,019 \\
(0.006)\end{array}$ & $\begin{array}{c}-0.011 * * * \\
(0.0272)\end{array}$ \\
\hline Claims & $\begin{array}{c}0.005 \\
(0.006)\end{array}$ & $\begin{array}{c}0.006 \\
(0.0099)\end{array}$ & $\begin{array}{c}0.007 \\
(0.003)\end{array}$ & $\begin{array}{l}0.008 * * \\
(0.0037)\end{array}$ & $\begin{array}{c}0,001 \\
(0.008)\end{array}$ & $\begin{array}{c}0.013 * * \\
(0.0361)\end{array}$ & $0,012 * *$ & $\begin{array}{l}0.014 * * \\
(0.0114)\end{array}$ & $\begin{array}{c}0,005 \\
(0.004)\end{array}$ & $\begin{array}{c}0.002 \\
(0.0229)\end{array}$ & $\begin{array}{c}0,007 \\
(0.008)\end{array}$ & $\begin{array}{c}0.005 \\
(0.0039)\end{array}$ \\
\hline Originality & $\begin{array}{l}-0.708 \\
(0.539)\end{array}$ & $\begin{array}{c}-0.240 \\
(0.0242)\end{array}$ & $\begin{array}{l}-0.286 \\
(0.136)\end{array}$ & $\begin{array}{c}-0.173 \\
(0.0007)\end{array}$ & $\begin{array}{c}0,770 \\
(0.513)\end{array}$ & $\begin{array}{c}0.571 \\
(0.0234)\end{array}$ & $-0,010$ & $\begin{array}{c}-0.113 \\
(0.0004)\end{array}$ & $\begin{array}{l}0,889^{*} \\
(0.352)\end{array}$ & $\begin{array}{c}0.330 \\
(0.0058)\end{array}$ & $\begin{array}{l}-0,936 \\
(0.921)\end{array}$ & $\begin{array}{l}-0.889 * \\
(0.0204)\end{array}$ \\
\hline Generality & $\begin{array}{c}0.211 \\
(0.290)\end{array}$ & $\begin{array}{c}0.229 \\
(0.0128)\end{array}$ & $\begin{array}{c}0.233 \\
(0.093)\end{array}$ & $\begin{array}{l}0.300 * * \\
(0.0057)\end{array}$ & $\begin{array}{c}0,668 \\
(0.568)\end{array}$ & $\begin{array}{c}0.506^{*} \\
(0.0224)\end{array}$ & $-0,116$ & $\begin{array}{c}0.109 \\
(0.0007)\end{array}$ & $\begin{array}{c}0,026 \\
(0.229)\end{array}$ & $\begin{array}{c}0.108 \\
(0.0136)\end{array}$ & $\begin{array}{l}-1,020 \\
(0.720)\end{array}$ & $\begin{array}{c}0.027 \\
(0.0000)\end{array}$ \\
\hline Family size & $\begin{array}{c}0.001 \\
(0.001)\end{array}$ & $\begin{array}{c}0.001 * \\
(0.0098)\end{array}$ & $\begin{array}{l}0.007 * \\
(0.002)\end{array}$ & $\begin{array}{c}0.012 * * * \\
(0.0147)\end{array}$ & $\begin{array}{c}0,004 \\
(0.002)\end{array}$ & $\begin{array}{c}0.006 * \\
(0.0365)\end{array}$ & $0,023 * *$ & $\begin{array}{c}0.014 \\
(0.0078)\end{array}$ & $\begin{array}{c}0,001 \\
(0.001)\end{array}$ & $\begin{array}{c}0.001 * \\
(0.0204)\end{array}$ & $\begin{array}{c}0,014 \\
(0.007)\end{array}$ & $\begin{array}{c}0.005 \\
(0.0067)\end{array}$ \\
\hline Age control & $\mathrm{Y}$ & $\mathrm{Y}$ & & & $\mathrm{Y}$ & $\mathrm{Y}$ & & & $\mathrm{Y}$ & $\mathrm{Y}$ & & \\
\hline $\begin{array}{l}\text { Number of } \\
\text { observations }\end{array}$ & 2853 & 2853 & 2853 & 2853 & 3004 & 3004 & 3004 & 3004 & 3191 & 3191 & 3191 & 3191 \\
\hline & & & & & $\begin{array}{l}\text { end: }{ }^{*} p \\
\text { bust sta }\end{array}$ & $\begin{array}{l}* * p<0.0 \\
\text { erros ir }\end{array}$ & $\begin{array}{l}p<0.001 \\
\text { entheses }\end{array}$ & & & & & \\
\hline
\end{tabular}

